\title{
Trends in Socioeconomic and Racial/Ethnic Inequalities in Self-Assessed Health, Disability, and Mental Health in California: Findings from CHIS 2001-2011
}

\author{
Jong Won Min
}

Received: 27 December 2013 / Revised: 26 February 2014 / Accepted: 30 June 2014 / Published online: 11 July 2014

(C) W. Montague Cobb-NMA Health Institute 2014

\begin{abstract}
Purpose Despite growing interest in health inequalities across socioeconomic and racial/ethnic groups, research remains scarce on the subject for California. The purpose of this study is to assess magnitude and trends in socioeconomic and race/ethnicity inequalities in self-assessed health, disability, and psychological distress.

Methods This study used the population-representative sample aged 45 and older $(n=181,964)$ in 2001-2011 California Health Interview Survey (CHIS). Based on poverty as socioeconomic position and race/ethnicity as nominal social group, health inequalities and the trend over time were examined by estimating population-weighted measures on both absolute and relative terms.

Results The most economically disadvantaged Californians showed the highest rates of poor self-assessed health, disability, and serious psychological distress for the entire study period. Socioeconomic health inequalities have widened in poor self-assessed health over time for women, while the inequalities appeared to narrow for disability and psychological distress for both men and women. Race/ethnicity inequalities in disability widened considerably for men and women, while those of psychological distress declined from 2005 to 2011.

Conclusion Socioeconomic and race/ethnicity health inequalities are present and persistent in California. Trends in health inequalities appear to reflect potential impact of recent financial crisis and legislative changes in California. Consistent measurement and monitoring of health inequalities are needed to develop socioeconomic and health policies that address health inequalities in California.
\end{abstract}

J. W. Min $(\bowtie)$

School of Social Work, San Diego State University, 5500 Campanile

Dr, San Diego, CA 92182, USA

e-mail: jwmin@mail.sdsu.edu
Keywords Socioeconomic health inequalities · Race/ ethnicity · Health disparities · Trend in health inequalities · Self-assessed health $\cdot$ Disability $\cdot$ Psychological distress

Health inequality has been widely documented across incomeor education-based socioeconomic groups and social groups like race/ethnicity. Many countries have striven to investigate the presence and magnitude of health inequalities, monitor its trends, and develop policy and programs aimed at reducing the health gaps. Tackling health inequality continues to garner heightened urgency and becomes a growing policy priority in the USA as it adversely affects social justice, economic cost, and quality of life on both individual- and societal-levels [1].

The level of commitment to addressing health inequalities is found along action spectrum, ranging from recognition, measurement, will to take action, to comprehensive policy [2]. The effort in the USA appears to be in the stage of taking steps for action as seen in the Healthy People initiative and the Affordable Care Act [3]. Yet, health inequalities persist in the country, and more challenges still lie ahead in tackling them [4]. Any policy designed to reduce health inequalities is to build upon accurate measurement and monitoring of its trend over time, as it is a prerequisite to developing such strategies and programs [5]. Although measurement and monitoring alone may not solve the problem of health inequalities, it can identify areas that need attention in addressing health inequalities [6]. In the USA, Agency for Healthcare Research and Quality (AHRQ) release of Congress-mandated National Healthcare Disparities Report every year reflect ongoing federal government-level measurement and monitoring efforts [7-9].

Health inequality research in the USA appears to (1) place more focus on race/ethnicity than social class or socioeconomic position, (2) utilize varying measures of health inequalities, and (3) show lack of studies on the trends in health inequalities. First, while international research on health inequalities has 
focused on socioeconomic-based health inequalities, the USA primarily emphasizes racial/ethnic disparity in health, although both socioeconomic status and race/ethnicity have been discussed as central themes for health inequalities [8, 10-12]. Only a smaller number of studies have addressed health disparities in socioeconomic status as well as race/ethnicity [13]. Second, various analytic methods of measurement have been employed in assessing health inequalities in the USA. Different methods of measurement could describe different aspects of health inequalities $[14,15]$, but it may also complicate interpretation and evaluation of current status, let alone monitoring of the inequalities over time [12]. Methodology guidelines [16-18] suggest that summary measures of health inequality be population-weighted because they could account for changes over time in the distribution of all social groups and differences from the population average rate of health. Also, both absolute and relative measures should be presented together, since they often show divergent results on the extent and trend of health inequalities. Third, compared with international research [15, 19-24], studies on the trend in health inequalities based on the population-weighted measures remain relatively scarce in the USA. Only a few trend studies in health inequalities were available on such indicators as breast cancer-related mortality and incidence [12], infant mortality, health behaviors $[2,25,26]$, mental health care and service use [27-29], officebased and outpatient visit and medical expenditure [12], and life expectancy and cause-specific mortality [30].

In contrast to federal efforts in the USA [8], evidence on measurement of health inequalities and the trend over time is limited in California [31-34]. The state leads the nation in race and ethnic diversity with the largest minority population of 22.3 million, serving potentially as a natural laboratory to study efforts to reduce health inequalities. Given its significance, however, the state was rated less than favorable on some health or health access indicators such as infectious disease, lack of health insurance, and poor health days [35]. While some communities and private sectors in California have introduced the initiatives and efforts against health disparities $[8,36]$, the state still appears to be in the stage between "recognition" and "framing health disparities to take action," [36] lacking consistent measurement, reporting, and monitoring of health inequalities. Therefore, the purpose of this study is to assess the magnitude of both socioeconomic- and racial/ ethnic inequalities in physical and mental health and to analyze the trend from 2001 to 2011 in California.

\section{Methods}

Data

Data was drawn from a compilation of multi-year data from 2001-2011 California Health Interview Survey (CHIS). The
CHIS is a statewide population-based representative survey in California. As a biennial survey, six different survey data have been publicly released. The total sample (2001 to 2011) included 73,047 men and 108,917 women aged 45 years or over. Self-assessed health (SAH) was asked in all of six survey years, but disability and psychological distress measures were collected from 2005. Therefore, while the analysis of SAH from all survey years from 2001 to 2011 was conducted, that of disability and psychological distress was based on four survey years from 2005 to 2011, representing 51,224 men and 76,887 women.

\section{Measures}

Health Indicators Three health indicators were used to assess health status. First, self-assessed health (SAH) was selected as it has been studied consistently in international research on health inequalities [19-23]. It was measured with a single question ("Would you say that in general your health is.....?") with five responses: "excellent" "very good," "good," "fair," and "poor." "Fair" and "poor" categories were combined to represent an adverse health event of "poor" SAH, and such dichotomization of the health indicator has been extensively used to represent "less than good" or "poor" health status in the previous health inequalities research [19-23, 52]. Second, the level of disability was assessed by one composite variable available in CHIS. It measures a disability status caused by either physical, mental, or emotion condition, with $0=$ "not disabled" and $1=$ "disabled." The variable was adapted from the American Community Survey and was developed by CHIS from several variables on disability conditions [53, 54]. Finally, mental health status was assessed by the presence of serious psychological distress in the past month. Based on the Kessler-6 scale [37], those who scored 13 or more were considered as experiencing serious psychological distress.

Socioeconomic Position In calculating socioeconomic health inequalities, poverty-level was used as an indicator of socioeconomic position. It was based on the percentage of income relative to federal poverty level (FPL), and coded into four groups: 0 $99 \%, 100-199 \%, 200-299 \%$, and 300 \% FPL or above.

Race/Ethnicity Race/ethnicity was used to estimate race/ethnicity-based measure of health inequalities. Groups defined by the UCLA CHPR were recoded into five categories; White, Latino, Asian, African American, and Others. Others included Pacific Islander, American Indian/Alaskan Native, and other singles/multiple race.

\section{Data Analysis}

Rates for poor SAH, disability, and psychological distress were age adjusted by direct standardization. The reference 
populations used for the standardization for CHIS 2001 to 2009 and CHIS 2011/12 were from age distribution of California in Census 2000 and 2010, respectively. All analyses were stratified by gender. The selected measures of health inequality are regression-based measures that would weigh social groups by their population size and account for differences from the population average $[13,16]$.

For health inequalities among race/ethnic groups as nominal social groups, between-group variance (BGV) was used as an absolute measure and mean log deviation (MLD) as a relative measure [17]. The BGV is calculated by squaring the differences in group rates from the population average and weighting by population size. The between-group variance of zero indicates no inequality. The MLD summarizes the disproportionality between shares of health and shares and population [17]. The value of zero for both BGV and MLD is interpreted as no inequality.

For socioeconomic health inequalities, Slope Index of Inequality (SII) and the Relative Index of Inequality (RII) were calculated as the absolute and relative measures [14, $16,38]$. RII was one of the two suggested methods of measuring socioeconomic inequalities in health [39]. For the RII and the SII, a ridit score was calculated for each poverty category based on the midpoint of the range in the cumulative distribution of the population. The interpretation of SII is the absolute difference in the rates between the most advantaged and the most disadvantaged of the social groups, while RII is interpreted as relative difference in the rates between the top and bottom of social groups [16]. Generalized linear model procedure was employed to estimate log-binomial regression for RIIs with a logarithmic link function and for SIIs with an identity link function [40]. To test the trend in SII and RII over time, all survey years pooled and the two-way interaction term was included between a ridit variable and a survey year variable representing six time-periods for poor $\mathrm{SAH}$ and four time-periods for disability and psychological distress. The trend was tested for statistical significance at the 0.05 level, and corresponding $p$ values are reported.

Stata 12 [41] was used to estimate SII, RII, and their $95 \%$ confidence intervals to account for sampling design and correctly estimate standard errors. Race/ethnicity inequalities measures were calculated by using the grouped data [16].

\section{Results}

Demographic and Socioeconomic Characteristics

Table 1 presents demographic and socioeconomic characteristics of the respondents in 2001, 2005, and 2011 by gender. Also provided are overall age-adjusted rates of three health indicators used in the study. Both White male and female populations decreased by more than $10 \%$, while all other racial groups increased over the decade, with Hispanic adults growing by $29 \%$. Socioeconomic status as measured by poverty level showed gender differences; men reported approximately $20 \%$ increase in poverty rate from 2001 to 2011 , but women showed $5.5 \%$ decrease during the same period.

Overall, one-fourth of Californian men and women showed poor self-health rating. Over time, men with poor SAH increased about $4.7 \%$, but women with poor SAH decreased by $2.7 \%$. More women reported having been disabled than men. Similarly, women also reported higher rates of serious psychological distress during the past 30 days than men. Nevertheless, from 2005 to 2011, women showed greater reduction in the rates $(14.3 \%)$ than men $(2.8 \%)$.

Rates of Poor SAH, Disability, and Serious Psychological Distress

Table 2 shows age-adjusted rates of poor SAH, disability, and serious psychological distress by gender, according to poverty status. Figure 1 (left column) displays poverty status-specific trends of the health indicators for the entire study period. Clear socioeconomic gradients of poor SAH across poverty status were observed. From 2001 to 2011, the gaps remained steady across four poverty groups, showing that those under poverty reported highest level of poor SAH and those with $300 \%$ FPL or more the lowest rates of poor SAH. When examined separately for men and women, both men and women under poverty showed a decline in rates of poor $\mathrm{SAH}$, about 10 and $4 \%$, respectively. For men and women in the non-poverty groups, however, various levels of increase in poor SAH were reported, from 0.2 to $11.1 \%$.

For disability and psychological distress, similar social gradients according to four poverty groups were noted as seen in Fig. 1. Compared with 2005, the rates of disability and psychological distress decreased in 2011 for most poverty groups, and men in poverty status of 100-199 \% registered the largest decline of $44.3 \%$ over time, followed by women living under poverty line $(38.5 \%)$. Both men and women with FPL $300 \%$ or more, however, showed an increase in the rates of psychological distress in 2011.

\section{Socioeconomic Health Inequalities}

Socioeconomic measures of health inequalities are presented for 2001, 2005, and 2011 in Table 2 in both absolute (SII) and relative (RII) terms. The results of SII confirmed the presence of socioeconomic inequalities in poor SAH rates between the worst and best poverty-status groups. While the size of inequalities in poor $\mathrm{SAH}$ among men narrowed down from 0.60 to 0.54 , that of women has widened from 0.55 to 0.60 over ten-year period. However, the narrowing or widening trends of inequalities in poor SAH were not statistically significant, indicating that health inequalities persisted. Persistent 
Table 1 Socio-demographic characteristics of adults aged 45 and older in California: 2001 to 2011

\begin{tabular}{|c|c|c|c|c|c|c|c|c|}
\hline & \multicolumn{3}{|l|}{ Male } & \multicolumn{3}{|l|}{ Female } & \multicolumn{2}{|c|}{$\begin{array}{l}\text { Percent of change from } 2001 \text { to } \\
2011\end{array}$} \\
\hline & $\begin{array}{l}2001 \\
(n=12,177)\end{array}$ & $\begin{array}{l}2005 \\
(n=17,941)\end{array}$ & $\begin{array}{l}2011 \\
(n=10,618)\end{array}$ & $\begin{array}{l}2001 \\
(n=15,952)\end{array}$ & $\begin{array}{l}2005 \\
(n=12,562)\end{array}$ & $\begin{array}{l}2011 \\
(n=18,363)\end{array}$ & Male & Female \\
\hline Mean age & 59.5 & 59.4 & 59.3 & 60.8 & 60.8 & 60.5 & & \\
\hline (S.E.) & $(0.06)$ & $(0.06)$ & $(0.08)$ & $(0.05)$ & $(0.04)$ & $(0.06)$ & & \\
\hline \multicolumn{9}{|l|}{ Race/ethnicity } \\
\hline White & $65.7 \%$ & $64.2 \%$ & $54.8 \%$ & $64.2 \%$ & $62.8 \%$ & $55.8 \%$ & $-16.6 \%$ & $-13.1 \%$ \\
\hline Latino & 14.5 & 15.5 & 18.7 & 14.7 & 14.8 & 15.9 & 29.0 & 8.2 \\
\hline Asian & 10.4 & 11.0 & 11.5 & 11.4 & 12.5 & 12.8 & 10.6 & 12.3 \\
\hline African American & 6.0 & 5.5 & 6.6 & 6.2 & 6.1 & 6.3 & 10.0 & 1.6 \\
\hline Others $^{\mathrm{a}}$ & 3.4 & 3.8 & 8.4 & 3.5 & 3.8 & 9.2 & 147.1 & 162.9 \\
\hline \multicolumn{9}{|c|}{ Socioeconomic position (poverty as $\%$ of $\mathrm{FPL}^{\mathrm{b}}$ ) } \\
\hline $300 \%$ or above & $60.6 \%$ & $65.8 \%$ & $57.7 \%$ & $49.0 \%$ & $56.1 \%$ & $53.0 \%$ & $-4.8 \%$ & $8.2 \%$ \\
\hline $200-299 \%$ & 13.5 & 11.8 & 17.4 & 14.6 & 13.8 & 18.5 & 28.9 & 26.7 \\
\hline $100-199 \%$ & 16.7 & 14.8 & 13.9 & 21.8 & 18.7 & 14.1 & -16.8 & -35.3 \\
\hline $0-99 \%$ & 9.2 & 7.6 & 11.0 & 14.6 & 11.3 & 13.8 & 19.6 & -5.5 \\
\hline \multicolumn{9}{|l|}{ Health indicators } \\
\hline Poor self-assessed health & $23.3 \%$ & $23.6 \%$ & $24.4 \%$ & $26.2 \%$ & $27.2 \%$ & $25.5 \%$ & $4.7 \%$ & $-2.7 \%$ \\
\hline Disabled & - & 36.2 & 37.1 & - & 43.5 & 42.6 & 2.5 & -2.1 \\
\hline Serious psychological distress & - & 3.6 & 3.5 & - & 4.9 & 4.2 & -2.8 & -14.3 \\
\hline
\end{tabular}

${ }^{\text {a }}$ Others include Pacific Islander, American Indian/Alaskan Native, other single/multiple race, as per UCLA CHPR definition

${ }^{\mathrm{b}}$ FPL federal poverty level

socioeconomic inequalities were also observed from the absolute measures for disability and psychological distress as shown in Fig. 2. The trend analyses of the SII over time showed no significant changes in socioeconomic inequalities in all of the health indicators for both men and women alike. The only exception was a significant narrowing trend in health inequalities of psychological distress for women $(P=0.012)$.

For the relative measures of inequality, the values of RII for poor SAH remained above 2.00 for both men and women during the study period (see Table 2), indicating that those living under poverty were approximately two times more likely to report poor SAH than those living above $300 \%$ FPL or above. The $P$ values above 0.05 for the trend analysis showed that the gaps in poor SAH between the two extreme groups remained wide and persistent over the entire study period. Greater socioeconomic health inequalities were noted for psychological distress, with the RIIs exceeding 3.70 for men and 2.30 for women. Over time, inequalities in psychological distress appeared to show downward trend to some extent, but the decline was not significant either for men $(P=0.844)$ nor for women $(P=0.266)$.

Race/Ethnicity-Based Health Inequalities

Age-adjusted rates of poor SAH, disability, and serious psychological distress according to race/ethnicity are presented in
Table 3. Rates of poor SAH declined about $7-10 \%$ over time for White men and women and Latino women. In contrast, the rates of poor SAH for Asian men increased by $12.3 \%$. In particular, men from "Other" groups showed the largest gain (23.4\%). Disability rates by Asian men and women declined sharply from 2005 to 2011 (around $17 \%$ ), but Latino men showed substantial increase (11.4\%). For the rates of psychological distress, non-White groups of men and women reported varying levels of decline over time (18 to $56 \%$ ), with an exception of $20 \%$ increase by African American men. Both White men and women displayed slight increases in the rates of psychological distress by 4.0 and $5.7 \%$, respectively.

Table 3 also displays both absolute and relative measures of race/ethnicity health inequalities and changes in the inequalities from 2001 to 2011. For poor SAH, absolute race/ethnicity inequalities were the largest in 2011 for men $(B G V=103.9)$ and in 2001 for women $(\mathrm{BGV}=142.3)$. Relative measures of race/ethnicity inequalities (MLD) showed the identical pattern to the absolute measure of BGV. While race/ethnicity inequalities of poor SAH widened by 13-19\% for men over the decade, those for women narrowed by about $4-10 \%$. Both absolute and relative race/ethnicity inequalities of disability increased for both men and women. Most notably, relative race/ethnicity inequalities of disability in MLD have jumped by $215 \%$ from 2.6 in 2005 to 8.2 in 2011 . For psychological 
Table 2 Age-Adjusted Rates and Measures of Health Inequalities for Poor SAH, disability, and serious psychological distress by socioeconomic position: CHIS 2001-2011

\begin{tabular}{|c|c|c|c|c|c|c|c|c|}
\hline & \multicolumn{3}{|l|}{ Male } & \multicolumn{3}{|l|}{ Female } & \multicolumn{2}{|c|}{$\begin{array}{l}\text { Percent of change } \\
\text { from } 2001 \text { to } 2011\end{array}$} \\
\hline & 2001 & 2005 & 2011 & 2001 & 2005 & 2011 & Male & Female \\
\hline \multicolumn{9}{|l|}{ Poor SAH } \\
\hline FPL (300 \% or up) & $12.9 \%$ & $15.0 \%$ & $13.5 \%$ & $14.2 \%$ & $15.8 \%$ & $12.1 \%$ & $4.7 \%$ & $-14.8 \%$ \\
\hline FPL (200-299 \%) & 28.9 & 28.5 & 29.5 & 24.4 & 29.3 & 27.1 & 2.1 & 11.1 \\
\hline FPL (100-199 \%) & 40.2 & 41.5 & 40.3 & 37.1 & 44.2 & 40.4 & 0.2 & 8.9 \\
\hline FPL (0-99\%) & 55.3 & 55.0 & 49.6 & 56.8 & 57.7 & 54.6 & $\begin{array}{l}-10.3 \\
p \text { for trend }\end{array}$ & -3.9 \\
\hline SII $(95 \%$ CI $)$ & $\begin{array}{l}0.60 \\
(0.55,0.65)\end{array}$ & $\begin{array}{l}0.55 \\
(0.50,0.61)\end{array}$ & $\begin{array}{l}0.54 \\
(0.48,0.60)\end{array}$ & $\begin{array}{l}0.55 \\
(0.51,0.61)\end{array}$ & $\begin{array}{l}0.59 \\
(0.54,0.63)\end{array}$ & $\begin{array}{l}0.60 \\
(0.55,0.64)\end{array}$ & $p=0.074$ & $p=0.254$ \\
\hline RII (95\% CI) & $\begin{array}{l}2.27 \\
(2.11,2.43)\end{array}$ & $\begin{array}{l}2.07 \\
(1.89,2.25)\end{array}$ & $\begin{array}{l}1.99 \\
(1.81,2.17)\end{array}$ & $\begin{array}{l}2.15 \\
(2.02,2.28)\end{array}$ & $\begin{array}{l}2.07 \\
(1.92,2.22)\end{array}$ & $\begin{array}{l}2.24 \\
(2.06,2.41)\end{array}$ & $p=0.225$ & $p=0.320$ \\
\hline \multicolumn{9}{|l|}{ Disability } \\
\hline FPL (300 \% or up) & - & $31.3 \%$ & $29.5 \%$ & - & $35.2 \%$ & $32.6 \%$ & $-5.8 \%$ & $-7.4 \%$ \\
\hline FPL (200-299 \%) & & 43.9 & 40.7 & & 46.7 & 44.8 & -7.3 & -4.1 \\
\hline FPL (100-199 \%) & & 47.0 & 48.7 & & 56.3 & 54.1 & 3.6 & -3.9 \\
\hline FPL (0-99\%) & & 58.9 & 55.8 & & 63.2 & 59.9 & $\begin{array}{l}-5.3 \\
p \text { for trend }\end{array}$ & -5.2 \\
\hline SII $(95 \%$ CI $)$ & - & $\begin{array}{l}0.41 \\
(0.35,0.47)\end{array}$ & $\begin{array}{l}0.38 \\
(0.32,0.46)\end{array}$ & - & $\begin{array}{l}0.48 \\
(0.43,0.52)\end{array}$ & $\begin{array}{l}0.43 \\
(0.39,0.47)\end{array}$ & $p=0.275$ & $p=0.155$ \\
\hline RII $(95 \% \mathrm{CI})$ & - & $\begin{array}{l}1.03 \\
(0.89,1.16)\end{array}$ & $\begin{array}{l}0.97 \\
(0.81,1.13)\end{array}$ & - & $\begin{array}{l}1.02 \\
(0.93,1.11)\end{array}$ & $\begin{array}{l}0.95 \\
(0.86,1.05)\end{array}$ & $p=0.321$ & $p=0.424$ \\
\hline \multicolumn{9}{|l|}{ Serious psych. distress } \\
\hline FPL ( $300 \%$ or up) & - & $1.1 \%$ & $1.2 \%$ & - & $1.9 \%$ & $2.1 \%$ & $9.1 \%$ & $10.5 \%$ \\
\hline FPL (200-299 \%) & & 5.5 & 3.5 & & 5.3 & 4.0 & -36.4 & -24.5 \\
\hline FPL (100-199 \%) & & 7.9 & 4.4 & & 8.8 & 7.1 & -44.3 & -19.3 \\
\hline FPL (0-99 \%) & & 14.0 & 13.8 & & 15.6 & 9.6 & $\begin{array}{l}-1.4 \\
p \text { for trend }\end{array}$ & -38.5 \\
\hline SII $(95 \%$ CI $)$ & - & $\begin{array}{l}0.15 \\
(0.12,0.18)\end{array}$ & $\begin{array}{l}0.12 \\
(0.08,0.15)\end{array}$ & - & $\begin{array}{l}0.14 \\
(0.11,0.16)\end{array}$ & $\begin{array}{l}0.09 \\
(0.07,0.12)\end{array}$ & $p=0.086$ & $p=0.012$ \\
\hline RII (95 \% CI) & - & $\begin{array}{l}3.84 \\
(3.30,4.38)\end{array}$ & $\begin{array}{l}3.71 \\
(2.80,4.63)\end{array}$ & - & $\begin{array}{l}2.94 \\
(2.48,3.40)\end{array}$ & $\begin{array}{l}2.29 \\
(1.76,2.81)\end{array}$ & $p=0.844$ & $p=0.266$ \\
\hline
\end{tabular}

distress, race/ethnicity inequalities declined among both men and women. On the absolute terms (BGV), the decline for men and women were 32.1 and $44.7 \%$, respectively. Conversely, on the relative terms (MLD), race/ethnicity inequalities of psychological distress showed $51.7 \%$ decline for women from 73.9 in 2005 to 35.7 in 2011.

Figure 3 shows trends in race/ethnicity health inequalities as relative percent changes in both absolute and relative measures by gender for all the study periods. For men, trends in absolute and relative inequalities of poor SAH since 2001 were similar in that the race/ethnicity inequalities showed decline until 2007, then sharply increased (72\% for BGV and $69 \%$ for MLD) in 2009, and showed modest decline in 2011. For women, race/ethnicity inequalities in poor SAH in 2011 were somewhat attenuated, compared to 2001. Nevertheless, from 2005 to 2011, absolute and relative measures showed divergent patterns. While the relative inequality measure of MLD increased until 2009 and declined, the absolute measure of BGV declined until 2009, followed by an increase. For disability, both men and women showed widening race/ethnic inequalities in 2011, relative to 2001, as all of percent changes in 2011 stayed above zero. In particular, the relative measure of race/ethnic inequality in disability showed the dramatic increase of about $400 \%$ in 2009, despite the decline of absolute measure by $16 \%$. The trends in serious psychological distress show that race/ethnicity inequalities (in BGV and MLD) had general tendency to decline both men and women. The initial downward trend appeared to be followed by modest increase from 2009. Overall, as most of percent changes since 2005 moved below zero, pointing to narrowing of race/ethnicity inequalities in serious psychological distress, with the exception of $36 \%$ increase in MLD for men in 2009. 
(a) Poverty Level
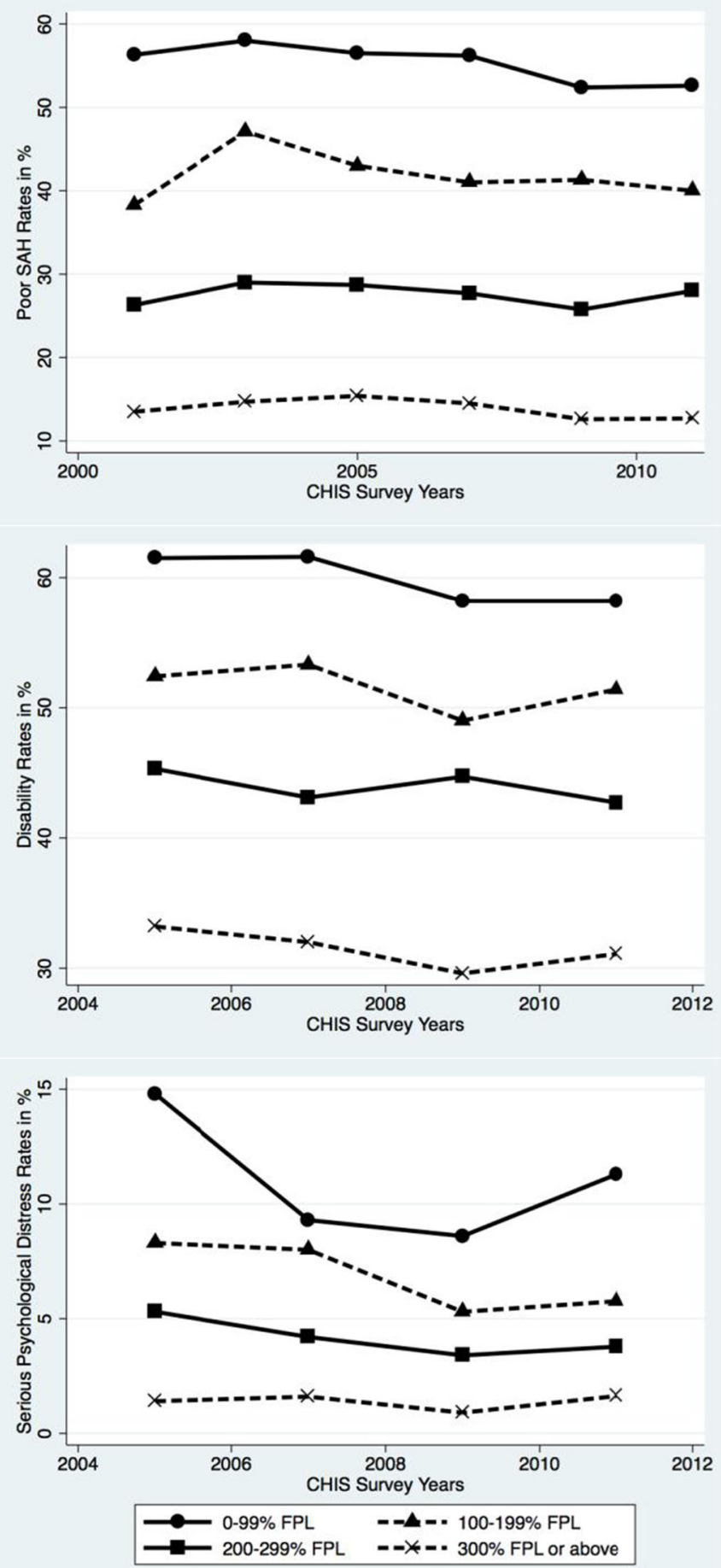

(b) Race/Ethnicity
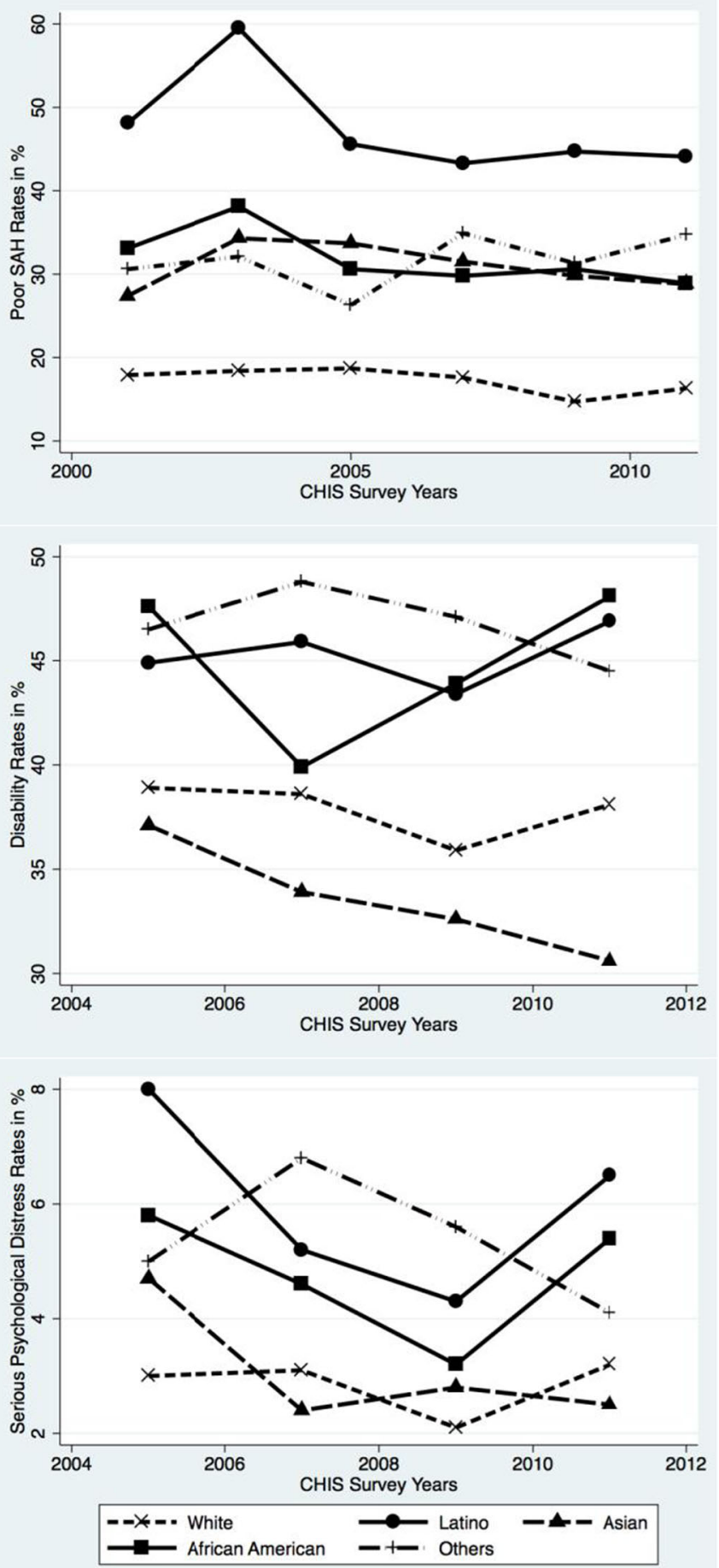

Fig. 1 Trends in age-adjusted rates of poor SAH, disability, and psychological distress by poverty level and race/ethnicity: CHIS 2001-2011

\section{Discussion}

This study examined the magnitude of socioeconomic and race/ethnic inequalities in poor $\mathrm{SAH}$, disability, and psychological distress and their trends from 2001 to
2011 in California. Inequalities in the health indicators were persistent across race/ethnicity as well as socioeconomic groups in California, consistent with previous studies in the USA $[3,4,7,25]$ and international research [15, 22-24]. 
Fig. 2 Trends in absolute and relative socioeconomic inequalities (SII and RII) in Poor $\mathrm{SAH}$, disability, and psychological distress over time by gender: CHIS 2001-2011
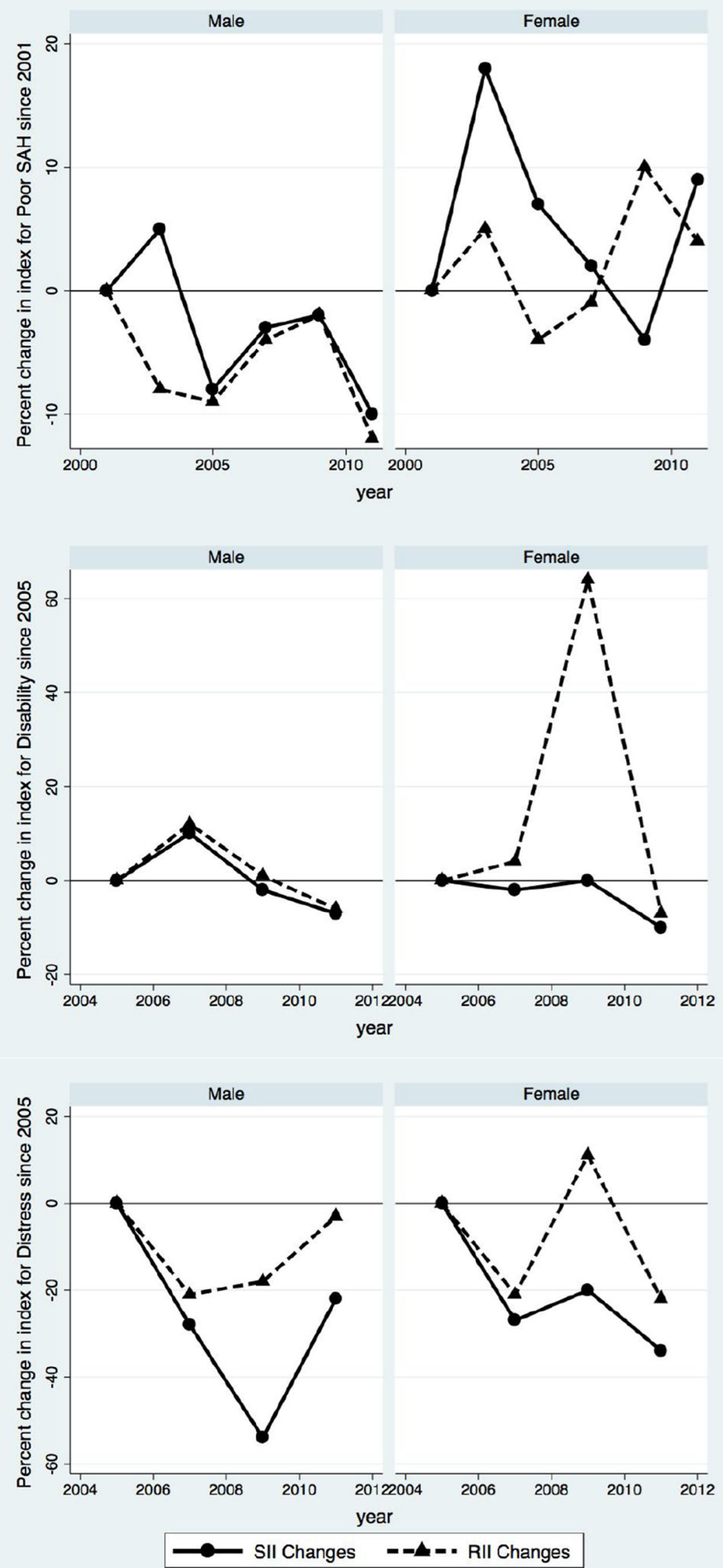
Table 3 Age-Adjusted Rates and Measures of Health Inequalities for Poor SAH, disability, and serious psychological distress by race/ethnicity: CHIS 2001-2011

\begin{tabular}{|c|c|c|c|c|c|c|c|c|}
\hline & \multicolumn{3}{|l|}{ Male } & \multicolumn{3}{|l|}{ Female } & \multicolumn{2}{|c|}{ Percent change } \\
\hline & 2001 & 2005 & 2011 & 2001 & 2005 & 2011 & Male & Female \\
\hline \multicolumn{9}{|l|}{ Poor SAH } \\
\hline White & $17.5 \%$ & $17.8 \%$ & $16.2 \%$ & $18.4 \%$ & $19.5 \%$ & $16.4 \%$ & $-7.4 \%$ & $-10.9 \%$ \\
\hline Latino & 43.7 & 40.8 & 42.1 & 51.7 & 50.0 & 46.2 & -3.7 & -10.6 \\
\hline Asian & 25.2 & 33.2 & 28.3 & 29.1 & 34.0 & 29.2 & 12.3 & 0.3 \\
\hline African American & 31.2 & 24.9 & 26.3 & 34.8 & 35.0 & 31.8 & -15.7 & -8.6 \\
\hline Others & 26.9 & 21.7 & 33.2 & 33.9 & 30.1 & 35.9 & 23.4 & 5.9 \\
\hline BGV & 87.0 & 77.8 & 103.9 & 142.3 & 123.9 & 128.6 & $19.4 \%$ & $-9.6 \%$ \\
\hline $\operatorname{MLD}(\times 1,000)$ & 66.3 & 58.9 & 74.6 & 88.4 & 71.8 & 85.2 & 12.5 & -3.6 \\
\hline \multicolumn{9}{|l|}{ Disability } \\
\hline White & - & $36.5 \%$ & $35.9 \%$ & - & $41.3 \%$ & $40.2 \%$ & $-1.6 \%$ & $-2.7 \%$ \\
\hline Latino & & 38.7 & 43.1 & & 50.3 & 50.9 & 11.4 & 1.2 \\
\hline Asian & & 33.0 & 27.4 & & 40.3 & 33.1 & -17.0 & -17.9 \\
\hline African American & & 41.6 & 43.6 & & 52.3 & 51.8 & 4.8 & -1.0 \\
\hline Others & & 40.4 & 44.6 & & 52.1 & 44.5 & 10.4 & -14.6 \\
\hline BGV & - & 13.9 & 25.7 & - & 18.7 & 31.2 & $84.0 \%$ & $66.8 \%$ \\
\hline $\operatorname{MLD}(\times 1,000)$ & - & 4.6 & 6.8 & - & 2.6 & 8.2 & 47.8 & 215.4 \\
\hline \multicolumn{9}{|l|}{ Serious psych. distress } \\
\hline White & - & $2.5 \%$ & $2.6 \%$ & - & $3.5 \%$ & $3.7 \%$ & $4.0 \%$ & $5.7 \%$ \\
\hline Latino & & 7.1 & 5.8 & & 8.8 & 7.2 & -18.3 & -18.2 \\
\hline Asian & & 3.3 & 2.5 & & 5.7 & 2.5 & -24.2 & -56.1 \\
\hline African American & & 4.5 & 5.4 & & 6.9 & 5.3 & 20.0 & -23.2 \\
\hline Others & & 4.2 & 2.6 & & 5.9 & 5.4 & -38.1 & -8.5 \\
\hline BGV & - & 2.8 & 1.9 & - & 3.8 & 2.1 & $-32.1 \%$ & $-44.7 \%$ \\
\hline $\operatorname{MLD}(\times 1,000)$ & - & 93.5 & 92.4 & - & 73.9 & 35.7 & -1.2 & -51.7 \\
\hline
\end{tabular}

While overall rates of the poor SAH declined over the time, the gap between the most advantaged and the most disadvantaged groups remained unchanged for men and women. Despite the persistence of health inequalities, however, substantial fluctuations in the inequalities should also be noted from the findings. While the degree of socioeconomic inequalities (in terms of poverty status) appeared to be relatively stable for poor SAH and disability, inequalities in psychological distress among female did appear to go from a widening between the below poverty-line group to a narrowing of that gap until 2008, and they again grew wider in 2011. In addition, there existed wide health gaps across the racial and minority groups in California. The degree of race/ethnic inequalities also showed a great deal of fluctuations on all three indicators. Especially, Latinos and African-Americans were worse off on all of the health indicators than the other groups. In California, the trend in the health inequalities over the 10-year period showed very complex and mixed patterns, depending on the indicators and gender. Such patterns also appear to mirror earlier studies. Some studies [20, 21] showed stability in socioeconomic inequalities of $\mathrm{SAH}$ over time, while others $[15,19]$ reported on consistently increasing trend over time.
SAH is known to have the shortest lag [20] in displaying the health effect of economic condition as it is the most subjective measure of health. Economic crisis may lead to growing income inequality, thereby affecting people's perception of health and widening health inequality [20, 42, 43]. A nationwide financial crisis of 2008, coupled with a growing income inequality in California (Gini index of over 0.45 ) may explain the observed persistence of health inequalities in poor SAH over time.

Although disability was much broadly defined than other studies [44, 45], the widening race/ethnicity inequalities in disability were confirmed for Californian adult population, particularly in absolute terms for men and in relative terms for women. It is a cause for concern due to its potential impact on quality of life and social/ economic consequence of dependency [45]. The observed increases seem to coincide with or at least reflect the aftermath of the 2008 recession mentioned above. In fact, the Social Security Administration reported an increase of $12.6 \%$ for disability benefits award and $21 \%$ increase in the number of applications to the Social Security Disability Insurance, following the economic crisis [55]. In addition, the crisis had taken greater toll on racial/ethnic 
Fig. 3 Trends (percent change from the first year of observation) in absolute and relative race/ethnicity inequalities (BGV and MLD) in poor SAH, disability, and psychological distress by gender: CHIS 2001-2011
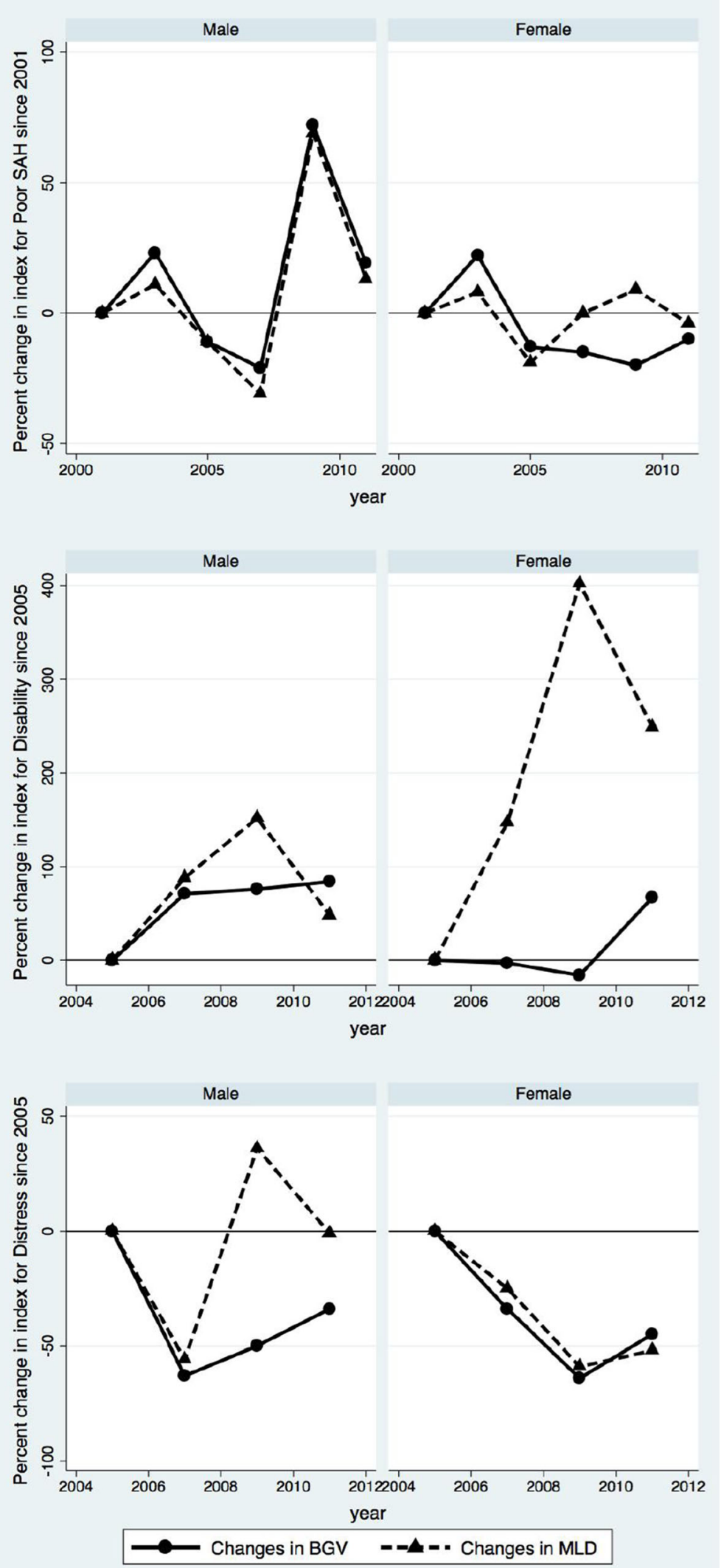

* The percent of change in BGV and MLD from the values in 2001 (for poor SAH) and in 2005 (for disability and psychological distress) 
minorities, especially among African American and Latinos, as evidenced by greater loss of wealth and assets and higher rates of foreclosure [56]. Taken together, the increases in racial/ethnic disparities in disability among African American and Latinos in this study may be closely associated with the differential impact of the financial crisis.

Finally, while rates of psychological distress remained somewhat stable with slight downward trends for those nonbelow-poverty-level groups, increasing trend was obvious for below-poverty (0-99 \% FPL) group from 2009. In terms of racial/ethnic groups, the downward trend from White, African Americans, and Latinos was followed by the increase since 2009. This observed pattern may be also related to the financial crisis, given its close association with mental health [57]. On the other hand, both socioeconomic- and race/ethnichealth inequalities showed generally downward trends from 2005 and 2011 for both men and women, although they increased for men in relative terms in 2009 , followed by the decline in 2011. No clear insight based on empirical analysis can be offered in this study on how to explain the overall downward trends in health inequalities in psychological distress. However, it is worthwhile to note that the Mental Health Services Act (MHSA) of 2004 was passed to expand mental health services in California that included prevention and early intervention (PEI) services, suicide prevention, and treatment services. Given the fact that the MHSA became effective in 2005 from which CHIS started measuring psychological distress, the results afford an opportunity to speculate about the potential effect of the MHSA on psychological distress as an indicator of population health. Nevertheless, despite strong adoption of PEI strategies and focus on disparities in access to mental health services [46, 47], no direct association can be drawn between the declining rates and inequality trend and the impact of the MHSA. Therefore, the results suggest that more formal examination and research is needed in order to investigate the association between levels and changes in inequalities and key economic changes or healthcare-related legislation. Furthermore, it is also necessary to continue to examine and track health inequalities with regard to different subgroups (e.g., by education or occupation) and other health and health access indicators.

A final point is that this study provides possible evidence that race/ethnicity-based health inequalities differentially affect different minority groups. For example, unlike African Americans and Latinos during the same period, AsianAmericans in California showed improved levels of selfassessed health, disability, and psychological distress, especially the rate of disability increasingly lower levels than Whites over time. Although a definite and reliable conclusion cannot be readily drawn from this study due to the aggregation of diverse Asian groups into one group and the relatively smaller sample size of this subgroup, it may suggest that health inequalities over time may be a confluence of race/ethnicity with socioeconomic levels manifested in a very complex manner.

Findings from the present study should be interpreted with the following limitations in mind. First, while socioeconomic health inequalities can be investigated across income, education, or social class, only poverty status was used in this study to examine health inequalities. For a fuller picture of socioeconomic health inequalities, future research should include income, education, or occupation-based socioeconomic groups for different perspective of health inequalities. Second, this study only focused on health inequalities in terms of some selected health status, although health inequalities could encompass inequalities in health access or health care quality. Third, health is a complex construct that builds on both objective and subjective assessment. All of the indicators used in the study are primarily based on self-reporting of health status, rather than any medical diagnosis of acute or chronic health conditions which should also be studied.

Literature highlights health and other socioeconomic policy as potential solution or the most important medicine in addressing health inequalities in nations [48-50]. The Nordic European countries showed favorable changes in health inequalities despite adverse impact of the economic crises on health. It was attributed to economic development and socioeconomic policies that moderated such adverse effect of the economic crises [21]. Therefore, we should take proactive and concerted efforts toward a development of systematic and comprehensive policy aimed at reducing the persistent socioeconomic and race/ethnicity health inequalities not only in the USA, but also in California. For that, a system of monitoring and tracking the magnitude and trends over time should be developed as found in Europe [15] or the English Indices of Deprivation in Great Britain [51]. Monitoring health inequalities is the first and the most significant step in reducing health inequalities. Such efforts provide detailed description of health indicators, methods, measurement, and monitoring of health inequities, paving the ways to identify determinants or pathways [50] for socioeconomic-based and race/ethnicitybased health inequalities. Only then, we can develop health and socioeconomic policies to move forward with more effective efforts to tackle health inequalities.

Conflict of Interest Author Jong Won Min declares that he has no conflict of interest.

Informed Consent "All procedures followed were in accordance with the ethical standards of the responsible committee on human experimentation (institutional and national) and with the Helsinki Declaration of 1975 , as revised in 2000 (5). Informed consent was obtained from all patients for being included in the study."

Animal Studies "No animal or human studies were carried out by the authors for this article." 


\section{References}

1. LaVeist VT, Gaskin, DJ, Richard P. The economic burden of health inequalities in the United States. 2009. Joint Center for Political and Economic Studies. Available at http://www.jointcenter.org.

2. Whitehead M. Diffusion of ideas on social inequalities in health: a European perspective. Milbank Q. 1998;76:469-92.

3. Bleich SN, Jarlenski MP, Bell CN, LaVeist TA. Health inequalities: trends, progress, and policy. Annu Rev Public Health. 2012;33:7-40. doi:10.1146/annurev-publhealth-031811-124658.

4. Adler NE, Rehkopf DH. U.S. disparities in health: descriptions, causes, and mechanisms. Annu Rev Public Health. 2008;29:235-52.

5. Houweling TA, Kunst AE, Mackenbach JP. Measuring health inequality among children in developing countries: does the choice of the indicator of economic status matter? Int $\mathrm{J}$ Equity Health. 2003;2(1):8. doi:10.1186/1475-9276-2-8.

6. Low A, Low A. Importance of relative measures in policy on health inequalities. BMJ. 2006;332(7547):967-9.

7. AHRQ, 2013; National Healthcare Quality \& Disparities Reports. July 2013. Agency for Healthcare Research and Quality, Rockville, MD. http://www.ahrq.gov/research/findings/nhqrdr/index.html

8. Institute of Medicine. How far have we come in reducing health disparities? Progress since 2000: workshop summary. Washington: The National Academies Press; 2012.

9. Truman BI, Smith KC, Roy K, et al. Rationale for regular reporting on health disparities and inequalities-United States. MMWR Surveill Summ. 2011;60(Suppl):3-10.

10. Phelan JC, Link BG, Tehranifar P. Social conditions as fundamental causes of health inequalities: theory, evidence, and policy implications. J Health Soc Behav. 2010;51(Suppl):S28-40. doi:10.1177/ 0022146510383498.

11. Kawachi I, Daniels N, Robinson DE. Health disparities by race and class: why both matter. Health Aff (Millwood). 2005;24(2):343-52.

12. Lê Cook B, McGuire TG, Zuvekas SH. Measuring trends in racial/ ethnic health care disparities. Med Care Res Rev. 2009;66(1):23-48. doi:10.1177/1077558708323607.

13. Harper S, Lynch J, Meersman SC, et al. Trends in areasocioeconomic and race-ethnic disparities in breast cancer incidence, stage at diagnosis, screening, mortality, and survival among women ages 50 years and over (1987-2005). Cancer Epidemiol Biomarkers Prev. 2009;18(1):121-31. doi:10.1158/1055-9965.EPI-08-0679.

14. Mackenbach JP, Kunst AE. Measuring the magnitude of socioeconomic inequalities in health: an overview of available measures illustrated with two examples from Europe. Soc Sci Med. 1997;44(6):757-71.

15. Spinakis A, Anastasiou G, Panousis V et al. Expert review and proposals for measurement of health inequalities in the European Union Full Report. European Commission Directorate General for Health and Consumers. Luxembourg. 2011. ISBN 978-92-79-18528-1.

16. Harper S, Lynch J. Methods for Measuring Cancer Disparities: Using Data Relevant to Healthy People 2010 Cancer-Related Objectives. NCI Cancer Surveillance Monograph Series, Number 6. Bethesda, MD: National Cancer Institute, 2005. NIH Publication No. 05-5777.

17. Harper S, Lynch J, Meersman SC, et al. An overview of methods for monitoring social disparities in cancer with an example using trends in lung cancer incidence by area-socioeconomic position and raceethnicity, 1992-2004. Am J Epidemiol. 2008;167:889-99. doi:10. 1093/aje/kwn016.

18. Keppel K, Pamuk E, Lynch J, et al. Methodological issues in measuring health disparities. Vital Health Stat 2. 2005 Jul;(141):1-16. Available at http://www.cdc.gov/nchs/data/series/sr 02/sr02 141.pdf

19. Dalstra JA, Kunst AE, Geurts JJ, et al. Trends in socioeconomic health inequalities in the Netherlands, 1981-1999. J Epidemiol Community Health. 2002;56(12):927-34.
20. Krokstad S, Kunst AE, Westin S. Trends in health inequalities by educational level in a Norwegian total population study. J Epidemiol Community Health. 2002;56(5):375-80.

21. Kunst AE, Bos V, Lahelma E, et al. Trends in socioeconomic inequalities in self-assessed health in 10 European countries. Int $\mathrm{J}$ Epidemiol. 2005;34(2):295-305.

22. Hosseinpoor AR, Stewart Williams JA, Itani L, Chatterji S, Hosseinpoor AR, Stewart Williams JA, et al. Socioeconomic inequality in domains of health: results from the World Health Surveys. BMC Public Health. 2012;12:198. doi:10.1186/14712458-12-198.

23. Mackenbach JP. Health inequalities, Europe in profile. An independent, expert report commissioned by the UK Presidency of the EU (February 2006). Available at http://ec.europa.eu/health/ph determinants/socio.../ev_060302 rd06 en.pdf.

24. Mackenbach JP, Stirbu I, Roskam AJ, et al. Socioeconomic inequalities in health in 22 European countries. N Engl J Med. 2008;358(23): 2468-81. doi:10.1056/NEJMsa0707519.

25. Braveman PA, Cubbin C, Egerter S, Williams DR, Pamuk E. Socioeconomic disparities in health in the United States: what the patterns tell us. Am J Public Health. 2010;100 Suppl 1:S186-96. doi: 10.2105/AJPH.2009.166082.

26. Zhang Q, Wang Y. Trends in the association between obesity and socioeconomic status in U.S. adults: 1971 to 2000 . Obes Res. 2004;12(10):1622-32.

27. Ault-Brutus AA. Changes in racial-ethnic disparities in use and adequacy of mental health care in the United States, 1990-2003. Psychiatr Serv. 2012;63(6):531-40. doi:10.1176/appi.ps.201000397.

28. Lê Cook B, McGuire T, Miranda J. Measuring trends in mental health care disparities, 2000-2004. Psychiatr Serv. 2007;58:1533-40.

29. Blanco C, Patel S, Liu L, et al. National trends in ethnic disparities in mental health care. Med Care. 2007;45(11):1012-9.

30. Singh GK, Hiatt RA. Trends and disparities in socioeconomic and behavioural characteristics, life expectancy, and cause-specific mortality of native-born and foreign-born populations in the United States, 1979-2003. Int J Epidemiol. 2006;35(4):903-19.

31. Racial and Ethnic Disparities in Healthcare in California: California Fact Book. November, 2003, www.oshpd.ca.gov/HID/ Products/PatDischargeData/ResearchReports/EthnicRacialDisp/ RacialEthnicFactBook.pdf

32. Racial and Ethnic Disparities in Healthcare in California: California Fact Book 2010. Sacramento, CA: California Office of Statewide Health Planning and Development, Winter 2010. Available at http:// www.oshpd.ca.gov

33. Healthy People 2010 Leading Health Indicators: California Update, 2008. Data summary No. DS08-09000. September 2008. Center for Health Statistics. California Department of Public Health. Available at http://www.cdph.ca.gov/pubsforms/ Pubs/OHIRhp2010LeadingHealthIndicator2008.pdf

34. California Reducing Disparities Project (CRDP). Office of Multicultural Services. January 2010. California Department of Mental Health. Available at http://www.dmh.ca.gov/Multicultural Services/CRDP.asp

35. America's Health Rankings: A call to action for individuals and their communities - 2012 Edition. United Health Foundation. Available at http://www.americashealthrankings.org/

36. Institute of Medicine. Demographic changes, a view from California: implications for framing health disparities: workshop summary. Washington: The National Academies Press; 2010.

37. Kessler RC, Barker PR, Colpe LJ, et al. Screening for serious mental illness in the general population. Arch Gen Psychiatry. 2003;60(2): 184-9.

38. Kunst AE, Mackenbach JP. Measuring socioeconomic inequalities in health. Copenhagen: World Health Organization, Regional Office for Europe; 1995. 
39. Wagstaff A, Paci P, van Doorslaer E. On the measurement of inequalities in health. Soc Sci Med. 1991;33:545-57.

40. Ernstsen L, Strand BH, Nilsen SM, Espnes GA, Krokstad S. Trends in absolute and relative educational inequalities in four modifiable ischaemic heart disease risk factors: repeated cross-sectional surveys from the Nord-Trøndelag Health Study (HUNT) 1984-2008. BMC Public Health. 2012;12:266. doi:10.1186/1471-2458-12-266.

41. StataCorp. Stata Statistical Software: release 12. College Station: StataCorp LP; 2011.

42. Hildebrand V, Van Kerm P. Income inequality and self-rated health status: evidence from the European community household panel. Demography. 2009;46(4):805-25.

43. Kennedy BP, Kawachi I, Glass R, Prothrow-Stith D. Income distribution, socioeconomic status, and self rated health in the United States: multilevel analysis. BMJ. 1998;317(7163):917-21.

44. Schoeni RF, Martin LG, Andreski PM, Freedman VA. Persistent and growing socioeconomic disparities in disability among the elderly: 1982-2002. Am J Public Health. 2005;95(11):2065-70.

45. Freedman VA, Spillman BC, Andreski PM, et al. Trends in late-life activity limitations in the United States: an update from five national surveys. Demography. 2013;50(2):661-71. doi:10.1007/s13524012-0167-z.

46. Lee, D. (2011) Prevention and Early Intervention Trends Report 2011. Mental Health Services Oversight and Accountability Commission. Available at http://www.mhsoac.ca.gov/MHSOAC_Publications/ docs/PressReleases/2011/PEITrendsReport_05-11-11.pdf

47. Katherine E. Watkins, M. Audrey Burnam, Edward N. Okeke and Claude Messan Setodji (2012). Evaluating the Impact of Prevention and Early Intervention Activities on the Mental Health of California's Population. Available at http://calmhsa.org/wp-content/uploads/ 2012/09/TR1316_FNLCompiled.pdf. California Mental Health Services Authority (CalMHSA) and RAND Corporation.
48. Graham H. Building an inter-disciplinary science of health inequalities: the example of life course research. Soc Sci Med. 2002;55(11): 2005-16.

49. Whitehead M, Burström B, Diderichsen F. Social policies and the pathways to inequalities in health: a comparative analysis of lone mothers in Britain and Sweden. Soc Sci Med. 2000;50(2):255-70.

50. Adler NE, Newman K. Socioeconomic disparities in health: pathways and policies. Health Aff (Millwood). 2002;21(2): 60-76. doi:10.1377/hlthaff.21.2.60.

51. English indices of deprivation 2010. United Kingdom. Department for Communities and Local Government. 24 March 2011. Available at https://www.gov.uk/government/publications/english-indices-ofdeprivation-2010.

52. Spinakis, A., Anastasiou, G., Panousis, V., et al. (2011). Expert review and proposals for measurement of health inequalities in the European Union - Full Report. European Commission Directorate General for Health and Consumers. Luxembourg. ISBN 978-92-7918528-1.

53. California Health Interview Survey. CHIS 2005 adult survey. Los Angeles: UCLA Center for Health Policy Research; 2010.

54. U.S. Census Bureau. American Community Survey; Population: Question on Disability. Available at http://www.census.gov/acs/ www/Downloads/QbyQfact/disability.pdf

55. Social Security Administration. Selected Data from Social Security's Disability Program. Disabled worker beneficiary statistics by calendar year, quarter, and month. 2014. Available at http://www.ssa.gov/ OACT/STATS/dibStat.html.

56. Christian Gonzalez-Rivera, People of Color Hardest Hit by the Foreclosure Crisis, Greenlining Issue Brief, August 2009. Available at http://greenlining.org/wp-content/uploads/2013/02/ foreclosuresandpocbrief.pdf.

57. World Health Organization. Impact of economic crises on mental health. Regional Office for Europe. 2011. Available at http://www. euro.who.int/_data/assets/pdf file/0008/134999/e94837.pdf. 